\title{
Reduced grip strength is associated with progression of depressive status in chronic liver diseases
}

\author{
Hiroki Nishikawa ${ }^{1,2 \#}$, Kazunori Yoh ${ }^{1 \#}$, Hirayuki Enomoto ${ }^{1}$, Naoto Ikeda ${ }^{1}$, Tomoyuki Takashima ${ }^{1}$, \\ Nobuhiro Aizawa ${ }^{1}$, Takashi Nishimura ${ }^{1}$, Shuhei Nishiguchi ${ }^{3}$, Hiroko Iijima ${ }^{1}$ \\ ${ }^{1}$ Department of Internal Medicine, Division of Gastroenterology and Hepatology, Hyogo College of Medicine, Nishinomiya, Hyogo, Japan; ${ }^{2}$ Center \\ for Clinical Research and Education, Hyogo College of Medicine, Nishinomiya, Hyogo, Japan; Kano General Hospital, Osaka, Osaka, Japan \\ Contributions: (I) Conception and design: H Nishikawa, K Yoh, H Enomoto; (II) Administrative support: All authors; (III) Provision of study materials \\ or patients: H Nishikawa, K Yoh, H Enomoto, T Nishimura; (IV) Collection and assembly of data: All authors; (V) Data analysis and interpretation: \\ H Nishikawa, K Yoh, H Enomoto; (VI) Manuscript writing: All authors; (VII) Final approval of manuscript: All authors. \\ \#These authors equally contributed to this work. \\ Correspondence to: Hiroki Nishikawa, MD, PhD. Department of Internal Medicine, Division of Gastroenterology and Hepatology, Hyogo College of \\ Medicine, Nishinomiya, Hyogo. 1-1, Mukogawacho, Nishinomiyashi, Hyogo 663-8501, Japan. Email: nishikawa_6392_0207@yahoo.co.jp.
}

Background: The causal relationship between sarcopenia and depression in chronic liver disease (CLD) patients is unclear. To elucidate these issues, we aimed to investigate the impacts of muscle strength as assessed by grip strength (GS) and muscle mass as assessed by bioelectrical impedance analysis (BIA) on the progression of depression in CLD patients ( $\mathrm{n}=189,49$ cirrhotic cases, and 87 males).

Methods: The Beck Depression Inventory-2nd edition (BDI-II) was used for the evaluation of depression. Time interval from the date of baseline BDI-II and the first confirmed date of elevation of BDI-II score was calculated in each subject. We analyzed factors associated with the elevation of BDI-II score.

Results: The baseline mean BDI-II score was 8.4 (median value, 7). Depression (BDI-II score $>11$ ) was found in 63 patients (33.33\%). GS decline at baseline was found in 13 male patients (14.9\%) and 37 female patients (36.3\%). Skeletal muscle index (SMI) by BIA decline at baseline was found in 25 male patients $(28.7 \%)$ and 40 female patients (39.2\%). During the follow-up period, 84 patients (44.4\%) had the elevation of BDIII score. For all cases, the 1-, 2- and 3-year cumulative elevation rates of BDI-II score were 39.2\%, 46.6\% and $54.9 \%$. In patients with GS decline at baseline, the 1-, 2- and 3-year cumulative elevation rates of BDI-II score were $53.1 \%, 67.8 \%$ and $77.9 \%$, while in patients with GS non-decline at baseline, the 1-, 2- and 3-year cumulative elevation rates of BDI-II score were $34.4 \%, 39.8 \%$ and $47.4 \%$ ( $\mathrm{P}=0.0006)$. In patients with SMI decline at baseline, the 1-, 2- and 3-year cumulative elevation rates of BDI-II score were 43.5\%, 50.8\% and $62.1 \%$, while in patients with SMI non-decline at baseline, the 1-, 2- and 3-year cumulative elevation rates of BDI-II score were $36.9 \%, 44.5 \%$ and $51.0 \%(\mathrm{P}=0.2487)$. As per the multivariate analyses, only lower GS at baseline $(\mathrm{P}=0.0022)$ was identified to be a significant factor associated with the elevation of BDI-II score.

Conclusions: Reduced GS rather than loss of muscle mass can be independently associated with an elevated risk for the progression of depression.

Keywords: Chronic liver disease (CLD); depression; muscle function; muscle mass

Submitted Oct 19, 2020. Accepted for publication Jan 14, 2021.

doi: 10.21037/apm-20-2059

View this article at: http://dx.doi.org/10.21037/apm-20-2059 


\section{Introduction}

Depressive state seen in patients with chronic liver diseases (CLDs) is common (1-10). Even in CLD patients with an earlier disease stage, depressive manifestations can be frequently recognized compared to healthy individuals, and depression is a leading mental illness in CLD patients (7). In patients with persistent hepatitis $C$ virus (HCV) infection, anxiety, depression, and chronic fatigue are reported to be major psychiatric disorders $(11,12)$. Decrease of quality of life (QOL) and increase of health care costs have been shown in CLD patients with depressive state $(4,13)$. In cirrhotic patients, depression can be linked to adverse clinical outcomes. Pre-transplant depression can cause length of hospitalization and poorer survival after liver transplantation (14). However, it tends to be overlooked and this issue is not given full consideration in the current practice guidelines (1). Depression seems to be one of essential neurocognitive manifestations in CLD patients. The Beck Depression Inventory-2nd edition (BDI-II) is a representative screening tool for the severity of depression (15).

Sarcopenia is a condition in which skeletal muscle mass and strength or physical function are reduced (16). Primary sarcopenia is a condition in which skeletal muscle mass and strength or physical function decline with aging, while secondary sarcopenia is defined as a condition in which skeletal muscle mass and strength or physical function are impaired due to underlying diseases such as inflammatory diseases, malignancies, renal diseases, respiratory diseases, heart diseases and liver diseases (17). Regarding mechanisms of developing sarcopenia in patients with CLDs, involvements of various factors such as aging, protein energy malnutrition, signal transduction related to protein synthesis and degradation, cytokines such as myostatin (a myokine which inhibits skeletal muscle protein synthesis), hyperammonemia, chronic inflammation, and sex hormones have been reported (18-20). Sarcopenia can be associated with decreased QOL and adverse clinical outcomes such as mortality, increased length of hospital stay and severe infections in CLD patients (18,21-25). Thus, the relationship between sarcopenia and depression in CLD patients appears to be essential.

In our previous cross-sectional study, we demonstrated the close relationship between sarcopenia and depression in CLD patients (26). Chang et al. reported in their metaanalysis that sarcopenia was independently associated with depression in elderly people, while the causal relationship between sarcopenia and depression needs further studies (27). The causal relationship between sarcopenia and depression in CLD patients is also unclear. To elucidate these issues, we aimed to investigate the impacts of sarcopenia-related factors (i.e., muscle strength and muscle mass) on the progression of depression in CLD patients.

We present the following article in accordance with the STROBE reporting checklist (available at http://dx.doi. org/10.21037/apm-20-2059).

\section{Methods}

\section{Patients}

Using a retrospective computerized database, a total of 189 CLD individuals who visited our hospital between October 2012 and April 2018 were analyzed. Clinical features, BDIII scores and laboratory data recorded at baseline were collated. Diagnosis for cirrhosis was determined according to the current guidelines (28). In all analyzed patients, evaluation using BDI-II questionnaire was performed twice or more during the observation period. The follow-up intervals were determined by the attending physician, and the patient's free will was used to make decisions regarding entries on the BDI-II questionnaire. Time interval from the date of baseline BDI-II and the first confirmed date of elevation of BDI-II score was calculated in each subject. The most suitable intervention for each underlying liver disease was performed $(11,28-30)$. In this study, there was no patient receiving liver transplantation during the followup period. The study was conducted in accordance with the Declaration of Helsinki (as revised in 2013), and approval of ethics was obtained from the institutional review board in Hyogo College of Medicine Hospital (No. 3469) and individual consent for this retrospective analysis was waived. An opt out method was employed.

\section{BDI-II score and our study}

The BDI-II is a widely accepted screening tool for assessing the severity of depression (31,32). High reliability and internal consistency are involved in the BDI-II, and the Japanese version of the BDI-II has reported the similar internal reliability and validity compared to the original version (33). BDI-II is a self-administered questionnaire which consists of 21 items $(31,34)$. Each answer is assessed on a four-point scale (0 to 3 points) $(31,34)$. Higher BDIII score indicates a severer depressive condition. A Japanese 
researcher categorized patients into normal (BDI-II score, 0-10), minimal depressive state (BDI-II score, 11-16), mild depressive state (BDI-II score, 17-20), moderate depressive state (BDI-II score, 21-30), and severe depressive state (BDI-II score $\geq 31$ ), and defined depression as BDI-II score $\geq 11$. In the current analysis, this classification system was applied. We analyzed factors associated with the elevation of BDI-II score (i.e., progression of depressive state).

\section{Muscle strength and muscle mass measurement}

Muscle strength [grip strength (GS) in this study] measurement and muscle mass measurement at baseline were done based on the previous reports (17). GS of the left hand and the right hand were measured twice each, and the mean value of the better of the two was adopted. For the evaluation of muscle mass, bioelectrical impedance analysis (BIA) was performed using InBody 720 to calculate appendicular muscle mass. Skeletal muscle index (SMI) was calculated as sum of muscle mass in upper and lower extremities divided by height squared $\left(\mathrm{kg} / \mathrm{m}^{2}\right)$. Based on the criteria of Japanese Society of Hepatology (JSH), muscle strength weakness was diagnosed with a GS of $<26 \mathrm{~kg}$ for male and $<18 \mathrm{~kg}$ for female. Likewise, loss of muscle mass was diagnosed by a SMI of $<7.0 \mathrm{~kg} / \mathrm{m}^{2}$ for male and $<5.7 \mathrm{~kg} / \mathrm{m}^{2}$ for female on BIA (17). Impacts of baseline GS and SMI on the elevation of BDI-II score were examined.

\section{Statistical analysis}

Continuous variables were presented as mean value [ \pm standard deviation (SD)]. Our primary endpoint was the elevation of BDI-II score compared to the baseline BDI-II score. Cumulative elevation rates of BDI-II score were calculated by the Kaplan-Meier method and compared between groups by the log-rank test. Univariate and multivariate Cox proportional hazard models were employed for identifying significant factors associated with the elevation rates of BDI-II score, and the results were presented as hazard ratios (HRs) and $95 \%$ confidence intervals (CIs) with corresponding $\mathrm{P}$ value. In the univariate analysis, the cohort was divided into two categories using each median value. The JMP version 14.0 software (SAS Institute, Cary, NC, USA) was employed to analyze data statistically (significant level, $\mathrm{P}<0.05$ ).

\section{Results}

\section{Patient characteristics}

Of the 189 patients with CLDs, 87 (46.0\%) were males, and the mean $( \pm \mathrm{SD})$ age was $61.8 \pm 11.7$ years. The mean $( \pm \mathrm{SD})$ follow-up period was $1.3 \pm 1.1$ years. There were 140 patients $(74.1 \%)$ with non-cirrhosis and 49 patients $(25.9 \%)$ with cirrhosis. There was no patient with overt hepatic encephalopathy. The main liver disease etiology was HCV (160 cases, 84.7\%). The baseline mean ( \pm SD) BDI-II score was $8.4 \pm 7.3$ (median value, 7 ). Baseline BDI-II score $0-10$ (normal) was observed in 126 (66.7\%), 11-16 (minimal depressive state) in $41(21.7 \%), 17-20$ (mild depressive state) in 14 (7.4\%), 21-30 (moderate depressive state) in $4(2.1 \%)$, and $\geq 31$ (severe depressive state) in $4(2.1 \%)$. GS decline at baseline as defined by the JSH criteria was observed in 13 male patients (14.9\%) and 37 female patients (36.3\%). SMI decline at baseline as defined by the JSH criteria was observed in 25 male patients $(28.7 \%)$ and 40 female patients $(39.2 \%)$. Sarcopenia at baseline as defined by the JSH criteria was observed in 7 male patients $(8.0 \%)$ and 19 female patients (18.6\%). In patients with GS decline at baseline $(\mathrm{n}=50)$ and non-decline at baseline $(\mathrm{n}=139)$, there were 26 patients $(52 \%)$ and 39 patients $(28.1 \%)$ with SMI decline at baseline. In patients with depression at baseline (BDI-II score $\geq 11, \mathrm{n}=63), 20$ (31.7\%) had GS decline, and $24(38.1 \%)$ had SMI decline. The baseline clinical characteristics and laboratory data of all analyzed patients are summarized in Table 1.

\section{Cumulative elevation rate of BDI-II score for all cases $(n=189)$}

During the observation period, 84 patients (44.4\%) had the elevation of BDI-II score. For all cases, the 1-, 2- and 3-year cumulative elevation rates of BDI-II score were $39.2 \%$, $46.6 \%$ and $54.9 \%$ (Figure 1).

\section{Cumulative elevation rates of BDI-II score according to the cirrbosis status}

In cirrhotic cases $(\mathrm{n}=49)$, the 1 -, 2 - and 3 -year cumulative elevation rates of BDI-II score were $51.3 \%, 64.0 \%$ and $75.3 \%$ (Figure $2 A$ ). During the follow-up period, 30 cirrhotic patients $(61.2 \%)$ had the elevation of BDI-II 
Table 1 Baseline characteristics $(\mathrm{n}=189)$

\begin{tabular}{|c|c|}
\hline Baseline variables & All cases $(n=189)$ \\
\hline Age (years) & $61.8 \pm 11.7$ \\
\hline Gender, male/female & $87 / 102$ \\
\hline $\begin{array}{l}\text { Liver disease etiology } \\
\mathrm{HCV} / \mathrm{HBV} / \text { others }\end{array}$ & $160 / 15 / 14$ \\
\hline Presence of sarcopenia, yes/no & $26 / 163$ \\
\hline BDI-II score & $8.4 \pm 7.3$ \\
\hline Presence of cirrhosis, yes/no & $49 / 140$ \\
\hline Body mass index $\left(\mathrm{kg} / \mathrm{m}^{2}\right)$ & $23.0 \pm 3.4$ \\
\hline SMI $\left(\mathrm{kg} / \mathrm{m}^{2}\right)$, male & $7.7 \pm 0.9$ \\
\hline SMI $\left(\mathrm{kg} / \mathrm{m}^{2}\right)$, female & $5.9 \pm 0.6$ \\
\hline Grip strength $(\mathrm{kg})$, male & $35.3 \pm 8.8$ \\
\hline Grip strength (kg), female & $19.7 \pm 4.4$ \\
\hline Total bilirubin (mg/dL) & $0.9 \pm 0.5$ \\
\hline Serum albumin (g/dL) & $4.1 \pm 0.4$ \\
\hline Prothrombin time (INR) & $1.11 \pm 0.16$ \\
\hline Platelet count $\left(\times 10^{4} / \mathrm{mm}^{3}\right)$ & $15.9 \pm 6.2$ \\
\hline AST (IU/L) & $39.4 \pm 25.2$ \\
\hline ALT (IU/L) & $39.2 \pm 33.4$ \\
\hline eGFR $\left(\mathrm{mL} / \mathrm{min} / 1.73 \mathrm{~m}^{2}\right)$ & $83.9 \pm 20.6$ \\
\hline
\end{tabular}

Data are expressed as number or mean value (standard deviation). HCV, hepatitis C virus; HBV, hepatitis B virus; $\mathrm{BDI}-\mathrm{II}$, Beck depression inventory II; SMI, skeletal muscle index; AST, aspartate aminotransferase; ALT, alanine aminotransferase; eGFR, estimated glomerular filtration rate.

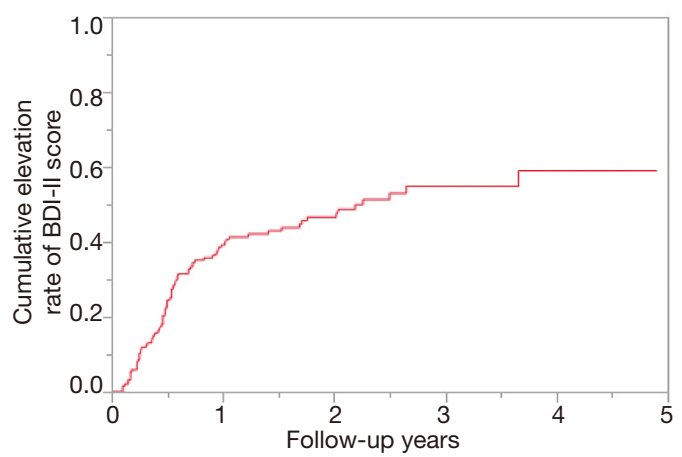

Figure 1 Cumulative elevation rate of BDI-II score for all cases $(\mathrm{n}=189)$. BDI-II, Beck Depression Inventory-2nd edition. score. In non-cirrhotic cases $(\mathrm{n}=140)$, the 1-, 2- and 3-year cumulative elevation rates of BDI-II score were $34.6 \%$, $40.4 \%$ and $46.8 \%$ (Figure $2 B$ ). During the follow-up period, 54 non-cirrhotic patients (38.6\%) had the elevation of BDIII score. The difference of cumulative elevation rates of BDI-II score between cirrhotic and non-cirrhotic cases was noted with significance $(\mathrm{P}=0.0112)$.

\section{Cumulative elevation rates of BDI-II score according to the $G S$ value and the SMI value}

In patients with GS decline at baseline $(\mathrm{n}=50)$, the 1-, 2and 3 -year cumulative elevation rates of BDI-II score were $53.1 \%, 67.8 \%$ and $77.9 \%$, while in patients with GS nondecline at baseline ( $\mathrm{n}=139)$, the 1 -, 2 - and 3 -year cumulative elevation rates of BDI-II score were $34.4 \%, 39.8 \%$ and 47.4\% $(\mathrm{P}=0.0006$, Figure $3 A)$.

In patients with SMI decline at baseline $(\mathrm{n}=65)$, the 1-, 2 and 3 -year cumulative elevation rates of BDI-II score were $43.5 \%, 50.8 \%$ and $62.1 \%$, while in patients with SMI nondecline at baseline $(\mathrm{n}=124)$, the 1 -, 2 - and 3 -year cumulative elevation rates of BDI-II score were $36.9 \%, 44.5 \%$ and $51.0 \%(\mathrm{P}=0.2487$, Figure $3 B)$.

\section{Predictors of the elevation of BDI-II score in all patients by univariate and multivariate analyses}

As per the univariate analyses, lower GS at baseline $(\mathrm{P}=0.0006)$, presence of cirrhosis $(\mathrm{P}=0.0113)$, aspartate aminotransferase (AST) $\geq 31 \mathrm{IU} / \mathrm{L}(\mathrm{P}=0.0193)$, and prothrombin time $(\mathrm{PT}-\mathrm{INR})>1.08(\mathrm{P}=0.0456)$ were found to be associated with the elevation of BDI-II score (Table 2). As per the multivariate analyses, only lower GS at baseline $(\mathrm{P}=0.0022)$ was identified to be a significant factor associated with the elevation of BDI-II score (Table 3). HRs and $95 \%$ CIs of lower GS at baseline, presence of cirrhosis, AST $\geq 31 \mathrm{IU} / 1$ and PT-INR $>1.08$ were shown in Table 3 .

\section{Cumulative elevation rates of BDI-II score according to the GS value and the SMI value in cirrbotic patients and non- cirrbotic patients}

Cirrhotic patients with GS decline at baseline $(\mathrm{n}=17)$ had significantly higher cumulative elevation rates of BDI-II score 

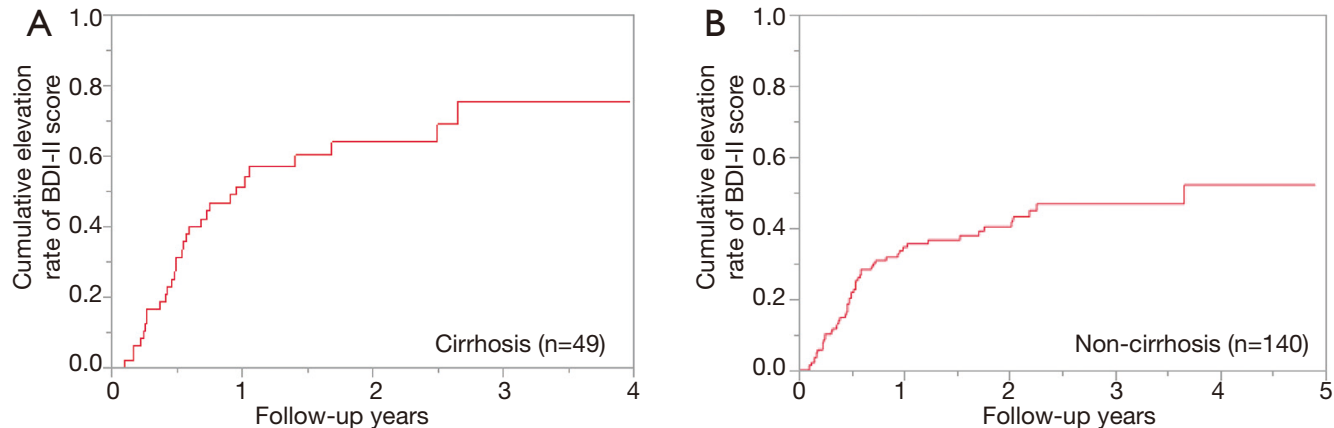

Figure 2 Cumulative elevation rate of BDI-II score in cirrhotic patients (n=49) (A) and non-cirrhotic patients (n=140) (B). BDI-II, Beck Depression Inventory-2nd edition.
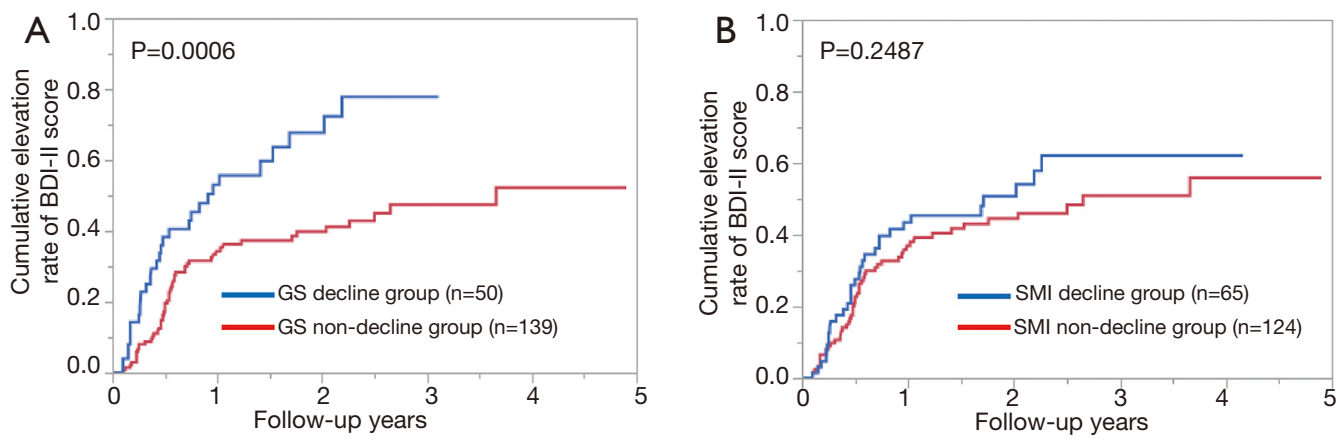

Figure 3 Cumulative elevation rate of BDI-II score according to the baseline GS decline (A) and according to the baseline SMI decline (B). BDI-II, Beck Depression Inventory-2nd edition; GS, grip strength; SMI, skeletal muscle index.

compared to those with GS non-decline at baseline $(\mathrm{n}=32)$ $(\mathrm{P}=0.0247$, Figure $4 A)$. Cirrhotic patients with SMI decline at baseline ( $n=16)$ tended to have significantly higher cumulative elevation rates of BDI-II score compared to those with SMI non-decline at baseline $(\mathrm{n}=33)(\mathrm{P}=0.0944$, Figure $4 B)$.

Non-cirrhotic patients with GS decline at baseline $(\mathrm{n}=33)$ had significantly higher cumulative elevation rates of BDIII score compared to those with GS non-decline at baseline $(\mathrm{n}=107)(\mathrm{P}=0.0335$, Figure $4 C)$. However, non-cirrhotic patients with SMI decline at baseline $(\mathrm{n}=49)$ did not have significantly higher cumulative elevation rates of BDI-II score compared to those with SMI non-decline at baseline $(\mathrm{n}=91)(\mathrm{P}=0.5943$, Figure $4 D)$.

\section{Cumulative elevation rates of BDI-II score according to the $G S$ value and the SMI value in patients aged 64 years or more and patients aged less than 64 years}

Patients aged 64 years (median age in this study) or more with GS decline at baseline ( $\mathrm{n}=37)$ had significantly higher cumulative elevation rates of BDI-II score compared to those with GS non-decline at baseline $(\mathrm{n}=64)(\mathrm{P}=0.0109$, Figure 5A). However, patients aged 64 years or more with SMI decline at baseline $(\mathrm{n}=44)$ did not have significantly higher cumulative elevation rates of BDI-II score compared to patients with SMI non-decline at baseline $(\mathrm{n}=57)$ ( $\mathrm{P}=0.0944$, Figure 5B).

Patients aged less than 64 years with GS decline at baseline $(n=13)$ had significantly higher cumulative elevation rates of BDI-II score compared to those with GS nondecline at baseline $(\mathrm{n}=75)(\mathrm{P}=0.0232$, Figure 5C). However, patients aged less than 64 years with SMI decline at baseline ( $\mathrm{n}=21)$ did not have significantly higher cumulative elevation rates of BDI-II score compared to patients with SMI non-decline at baseline $(\mathrm{n}=67)(\mathrm{P}=0.1396$, Figure $5 D)$.

\section{Cumulative elevation rates of BDI-II score according to the GS value and the SMI value in male and female patients}

Male patients with GS decline at baseline $(n=13)$ had 
Table 2 Univariate analyses of factors linked to the progression of depression ( $\mathrm{n}=189)$

\begin{tabular}{|c|c|c|}
\hline Baseline variables & Number of each category & Univariate $P$ value \\
\hline Gender, male/female & $87 / 102$ & 0.4173 \\
\hline Cause of liver diseases, HCV/HBV/others & $160 / 15 / 14$ & 0.2516 \\
\hline Grip strength at baseline, high/low & $139 / 50$ & 0.0006 \\
\hline Presence of cirrhosis at baseline, yes/no & $49 / 140$ & 0.0113 \\
\hline Presence of depression at baseline, yes/no & $63 / 126$ & 0.3616 \\
\hline AST $\geq 31 \mathrm{IU} / \mathrm{L}$, yes/no & $97 / 92$ & 0.0193 \\
\hline ALT $\geq 28$ IU/L, yes/no & $100 / 89$ & 0.2008 \\
\hline Prothrombin time $($ INR) $>1.08$, yes/no & $98 / 91$ & 0.0456 \\
\hline Platelet count $\leq 16.1 \times 10^{4} / \mathrm{mm}^{3}$, yes $/$ no & $95 / 94$ & 0.8675 \\
\hline eGFR $\leq 83 \mathrm{~mL} / \mathrm{min} / 1.73 \mathrm{~m}^{2}$, yes $/$ no & $96 / 93$ & 0.4427 \\
\hline Body mass index $\leq 22.7 \mathrm{~kg} / \mathrm{m}^{2}$, yes $/ \mathrm{no}$ & $98 / 91$ & 0.3971 \\
\hline
\end{tabular}

$\mathrm{HCV}$, hepatitis C virus; HBV, hepatitis B virus; AST, aspartate aminotransferase; ALT, alanine aminotransferase; eGFR, estimated glomerular filtration rate.

Table 3 Multivariate analyses of factors linked to the progression of depression.

\begin{tabular}{lccc}
\hline \multirow{2}{*}{ Baseline variables } & \multicolumn{3}{c}{ Multivariate analysis } \\
\cline { 2 - 4 } & Hazard ratio & 95\% confidence interval & P value \\
\hline Presence of cirrhosis & 1.362 & $0.806-2.300$ & 0.2483 \\
Low-GS at baseline & 2.037 & $1.291-3.216$ & 0.0022 \\
AST $\geq 31$ IU/L & 1.443 & $0.904-2.302$ & 0.1242 \\
PT $($ INR $)>1.08$ & 1.129 & $0.690-1.848$ & 0.6288 \\
\hline
\end{tabular}

GS, grip strength; AST, aspartate aminotransferase; PT, prothrombin time.

significantly higher cumulative elevation rates of BDI-II score compared to those with GS non-decline at baseline $(\mathrm{n}=74)$ $(\mathrm{P}=0.0113$, Figure $6 A)$. Likewise, male patients with SMI decline at baseline $(\mathrm{n}=25)$ had significantly higher cumulative elevation rates of BDI-II score compared to those with SMI non-decline at baseline $(\mathrm{n}=62)(\mathrm{P}=0.0403$, Figure $6 B)$.

Female patients with GS decline at baseline $(n=37)$ had significantly cumulative higher elevation rates of BDI-II score compared to those with GS non-decline at baseline $(\mathrm{n}=65)(\mathrm{P}=0.0170$, Figure 6C). However, female patients with SMI decline at baseline $(\mathrm{n}=40)$ did not have significantly higher cumulative elevation rates of BDI-II score compared to those with SMI non-decline at baseline $(\mathrm{n}=62)(\mathrm{P}=0.9134$, Figure $6 D)$.

\section{Cumulative elevation rates of BDI-II score according to the GS value and the SMI value in patients with baseline BDI-II score $\geq 11$ and baseline BDI-II score $\leq 10$}

Patients with baseline BDI-II score $\geq 11$ with GS decline 

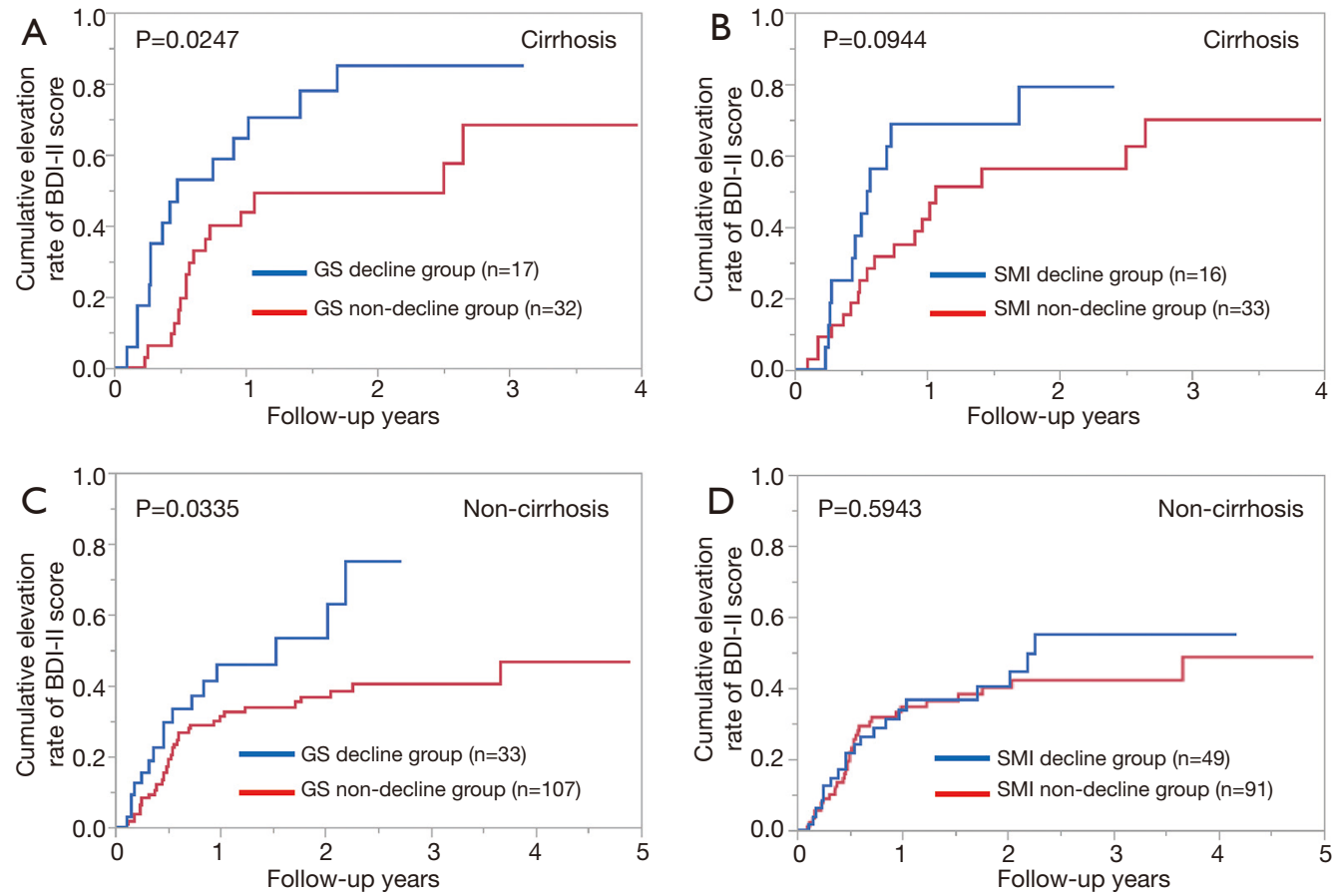

Figure 4 Cumulative elevation rate of BDI-II score according to the baseline GS decline (A) and the baseline SMI decline (B) in cirrhotic patients. Cumulative elevation rate of BDI-II score according to the baseline GS decline (C) and the baseline SMI decline (D) in noncirrhotic patients. BDI-II, Beck Depression Inventory-2nd edition; GS, grip strength; SMI, skeletal muscle index.
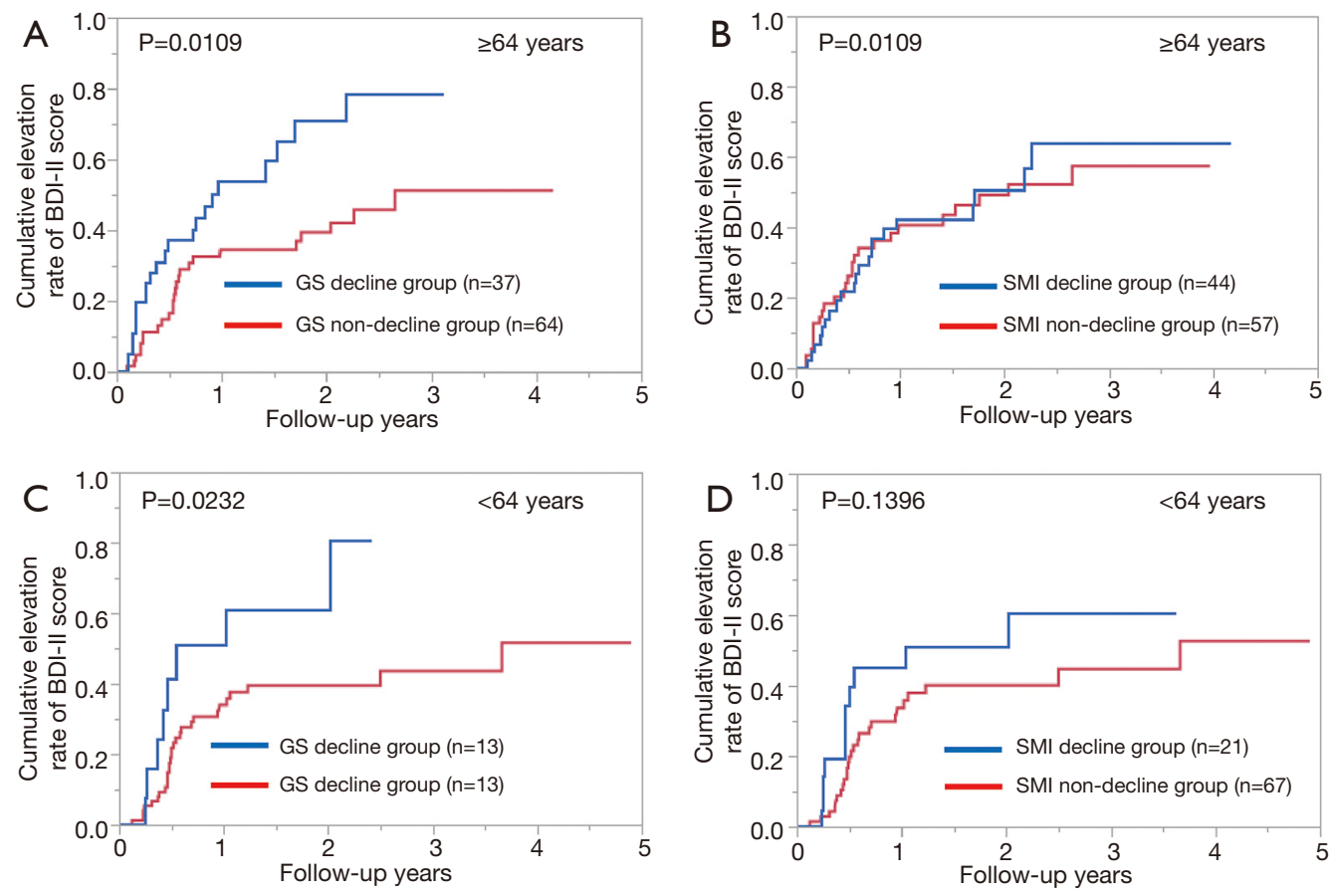

Figure 5 Cumulative elevation rate of BDI-II score according to the baseline GS decline (A) and the baseline SMI decline (B) in patients aged 64 years (median age) or more. Cumulative elevation rate of BDI-II score according to the baseline GS decline (C) and the baseline SMI decline (D) in patients less than 64 years. BDI-II, Beck Depression Inventory-2nd edition; GS, grip strength; SMI, skeletal muscle index. 

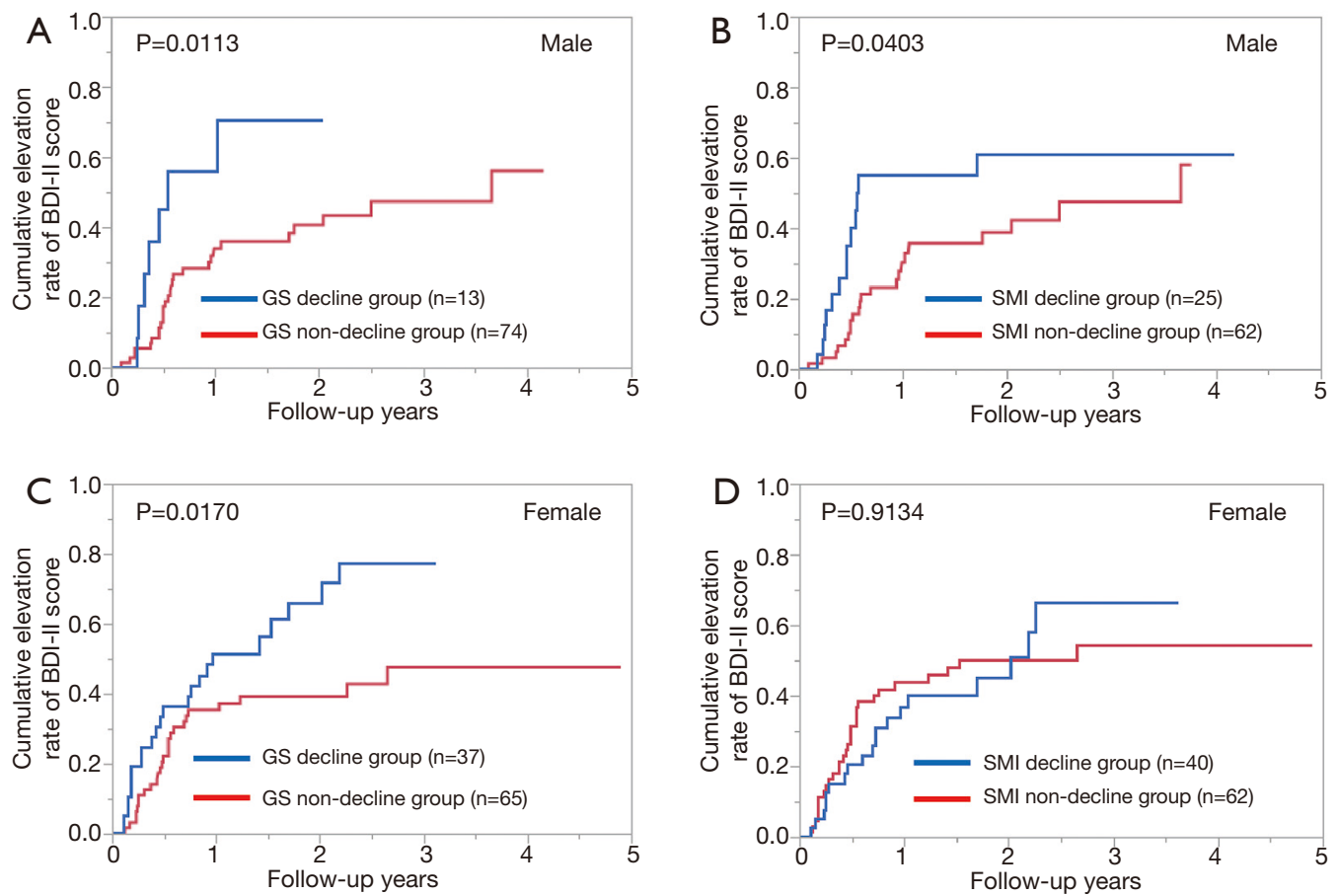

Figure 6 Cumulative elevation rate of BDI-II score according to the baseline GS decline (A) and the baseline SMI decline (B) in male patients. Cumulative elevation rate of BDI-II score according to the baseline GS decline (C) and the baseline SMI decline (D) in female patients. BDI-II, Beck Depression Inventory-2nd edition; GS, grip strength; SMI, skeletal muscle index.

at baseline $(n=20)$ had significantly higher cumulative elevation rates of BDI-II score compared to those with GS non-decline at baseline $(\mathrm{n}=43)(\mathrm{P}=0.0101$, Figure $7 A)$. Patients with baseline BDI-II score $\geq 11$ with SMI decline at baseline $(n=24)$ did not have significantly higher cumulative elevation rates of BDI-II score compared to those with SMI non-decline at baseline $(\mathrm{n}=39)(\mathrm{P}=0.2837$, Figure $7 B)$.

Patients with baseline BDI-II score $\leq 10$ with GS decline at baseline $(n=30)$ had significantly higher cumulative elevation rates of BDI-II score compared to those with GS non-decline at baseline $(\mathrm{n}=96)(\mathrm{P}=0.0187$, Figure $7 C)$. Likewise, patients with baseline BDI-II score $\leq 10$ with SMI decline at baseline $(\mathrm{n}=41)$ had significantly higher cumulative elevation rates of BDI-II score compared to those with $\mathrm{SMI}$ non-decline at baseline $(\mathrm{n}=85)(\mathrm{P}=0.0215$, Figure 7D).

\section{Discussion}

It is well accepted that particular cohorts of patients with chronic illnesses such as malignancies, musculoskeletal diseases, cardiovascular diseases and respiratory disease involve a much higher prevalence of affective disorders than the general population, which may be linked to poorer functional outcomes (35). Risk factors for the progression of depression in CLD patients are largely unknown. While skeletal muscle is also an endocrine organ that secretes myokines that regulate systemic glucose and lipid homeostasis and regulate protein synthesis and breakdown (i.e., protein turnover) in muscle tissue $(36,37)$. The causal relationship between depression and sarcopenia-related factors in CLD patients is also unclear. In the current study, we performed comprehensive analyses regarding the influence of sarcopenia-related factors at baseline on the elevation of BDI-II score in patients with CLDs. The multivariate analysis identified only GS decline at baseline as a significant adverse predictor linked to the elevation of BDI-II score. We therefore concluded that reduced GS rather than muscle mass was associated with the elevation of BDI-II score independent of age, cirrhosis status, gender and baseline depressive condition. The causal relationship between depression and sarcopenia-related factors in CLD patients was clarified to some extent through the current study. Depression is possibly linked to sarcopenia due to its 

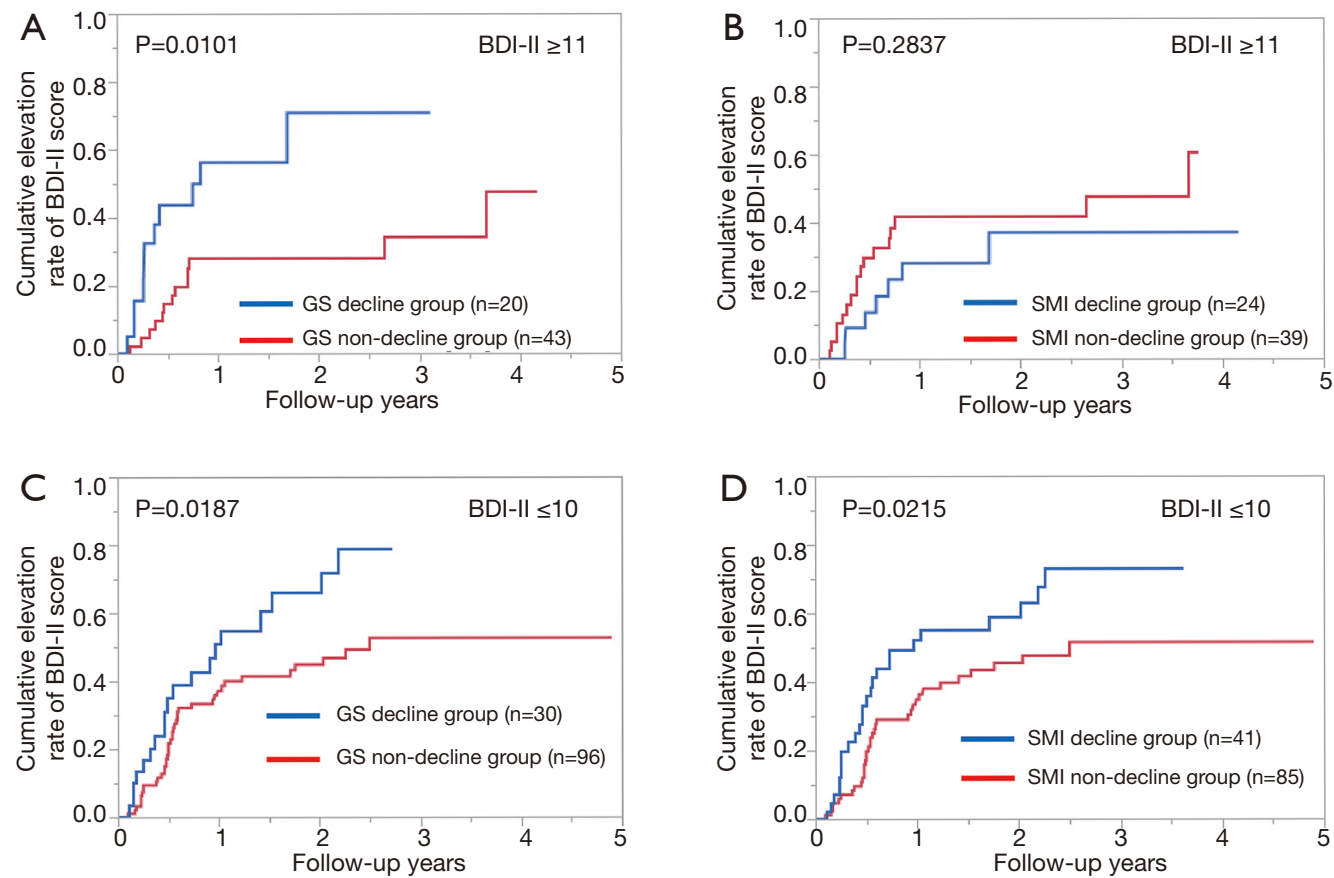

Figure 7 Cumulative elevation rate of BDI-II score according to the baseline GS decline (A) and the baseline SMI decline (B) in patients with baseline BDI-II score $>11$. Cumulative elevation rate of BDI-II score according to the baseline GS decline (C) and the baseline SMI decline (D) in patients with baseline BDI-II score $\leq 10$. BDI-II, Beck Depression Inventory-2nd edition; GS, grip strength; SMI, skeletal muscle index.

association with reduced mobility and ability to complete daily activities. A reduction in ability to complete these daily activities has been found to reduce QOL, in particular the mental components of QOL, which infer a potential increase in susceptibility to depression $(38,39)$. To the best of our knowledge, this is the first report demonstrating the impacts of sarcopenia-related factors on the progression of depression in patients with CLDs.

It is unclear why muscle weakness can better predict the exacerbation of depression in patients with CLDs compared to muscle mass loss. One possible reason for these is that muscle strength decline occurs $2-5$ times faster than muscle mass loss, which can be linked to the QOL decline, resulting in the elevation of BDI-II score (40). GS is representative of whole-body muscle strength and has been demonstrated to be an independent indicator of nutritional status (41). However, in male patients and in patients with baseline BDI-II $\leq 10$, the SMI decline group had significantly higher cumulative elevation rates of BDIII score compared to the SMI non-decline group. While the present study emphasizes the importance of GS on the progression of depression, it does not deny the importance of muscle mass on prognosis. Disease progression and QOL decline can also affect prognosis (39).

In the present study, one-third of analyzed subjects had BDI-II score $\geq 11$ at baseline. As mentioned earlier, presence of depression in CLDs tends to be overlooked despite of its prognostic impact. Clinicians should be aware of the high prevalence of depression in CLDs. During the follow-up period, 30 cirrhotic patients $(61.2 \%)$ had the elevation of BDI-II score, while 54 non-cirrhotic patients (36.2\%) had the elevation of BDI-II score, which was largely different from cirrhotic patients. Longer liver disease duration in cirrhotic patients and anxiety about having cirrhosis may be associated with the results. It is reported that over $30 \%$ of cirrhotic subjects had depressive features, and they experienced unfavorable clinical outcomes such as progression of depression or higher mortality than nondepressed cirrhotic subjects, which were in line with our data (9). In this study, sarcopenia as defined by the JSH criteria was observed in 7 men $(8.0 \%)$ and 19 women (18.6\%). The prevalence of sarcopenia, determined by the Asian Working Group of Sarcopenia 2014 criteria, was reported to be $9.6 \%$ for males and $7.7 \%$ for females in 
the 949 randomly selected general elderly population in Japan (42). Therefore, it was suggested that sarcopenia has a higher prevalence in female patients with CLDs than in the general elderly population. The reason for these may be linked to the influence of underlying liver diseases on muscle.

In patients with $\mathrm{HCV}(\mathrm{n}=160), 75$ patients $(46.9 \%)$ had the elevation of BDI-II score during the follow-up period. Most of these 75 patients received antiviral therapies with sustained virological response (SVR). SVR does not eliminate the possibility of liver carcinogenesis (43). Similarly, SVR does not solve the psychological problems in patients with HCV considering the current data. Clinicians should be fully aware of these. Post SVR surveillance in $\mathrm{HCV}$ patients will be needed.

The limitations of this study should be acknowledged. The retrospective nature of the study limits the evaluation of factors influencing the depressive state such as life circumstances or antidepressant medications. Additionally, our data were derived from Japanese CLD patient data; further examinations on other cohorts will be required to extend the application. Finally, several interventions for CLD patients during the follow-up period have been done, making bias for the disease progression. Thus, interpretation with caution to our results will be necessary.

In conclusion, we would like to emphasize the importance of muscle strength on depressive condition in CLDs. Our findings involve essential implications in clinical practice as they highlight that reduced GS rather than loss of muscle mass is independently associated with an elevated risk for the progression of depression.

\section{Acknowledgments}

The authors would like to thank Yasuko Higuchi in our hospital for the anthropometry measurement. This work was partly supported by Hyogo Innovative Challenge, Hyogo College of Medicine, Japan.

Funding: None.

\section{Footnote}

Reporting Checklist: The authors have completed the STROBE reporting checklist. Available at http://dx.doi. org/10.21037/apm-20-2059

Peer Review File: Available at http://dx.doi.org/10.21037/ apm-20-2059
Conflicts of Interest: All authors have completed the ICMJE uniform disclosure form (available at http://dx.doi. org/10.21037/apm-20-2059). The authors have no conflicts of interest to declare.

Ethical Statement: The authors are accountable for all aspects of the work in ensuring that questions related to the accuracy or integrity of any part of the work are appropriately investigated and resolved. The study was conducted in accordance with the Declaration of Helsinki (as revised in 2013), and approval of ethics was obtained from the institutional review board in Hyogo college of medicine hospital (No. 3469) and individual consent for this retrospective analysis was waived. An opt out method was employed.

Open Access Statement: This is an Open Access article distributed in accordance with the Creative Commons Attribution-NonCommercial-NoDerivs 4.0 International License (CC BY-NC-ND 4.0), which permits the noncommercial replication and distribution of the article with the strict proviso that no changes or edits are made and the original work is properly cited (including links to both the formal publication through the relevant DOI and the license). See: https://creativecommons.org/licenses/by-nc-nd/4.0/.

\section{References}

1. Buganza-Torio E, Mitchell N, Abraldes JG, et al. Depression in cirrhosis-a prospective evaluation of the prevalence, predictors and development of a screening nomogram. Aliment Pharmacol Ther 2019;49:194-201.

2. Peng JK, Hepgul N, Higginson IJ, et al. Symptom prevalence and quality of life of patients with end-stage liver disease: A systematic review and meta-analysis. Palliat Med 2019;33:24-36.

3. Yeoh SW, Holmes ACN, Saling MM, et al. Depression, fatigue and neurocognitive deficits in chronic hepatitis $\mathrm{C}$. Hepatol Int 2018;12:294-304.

4. Adinolfi LE, Nevola R, Rinaldi L, et al. Chronic Hepatitis C Virus Infection and Depression. Clin Liver Dis 2017;21:517-34.

5. Huang X, Liu X, Yu Y. Depression and Chronic Liver Diseases: Are There Shared Underlying Mechanisms? Front Mol Neurosci 2017;10:134.

6. Khanna A, Leighton J, Lee Wong L, et al. Symptoms of PBC - Pathophysiology and management. Best Pract Res Clin Gastroenterol 2018;34-35:41-7. 
7. Dirks M, Haag K, Pflugrad H, et al. Neuropsychiatric symptoms in hepatitis $\mathrm{C}$ patients resemble those of patients with autoimmune liver disease but are different from those in hepatitis B patients. J Viral Hepat 2019;26:422-31.

8. Schramm C, Wahl I, Weiler-Normann C, et al. Healthrelated quality of life, depression, and anxiety in patients with autoimmune hepatitis. J Hepatol 2014;60:618-24.

9. Mullish BH, Kabir MS, Thursz MR, et al. Review article: depression and the use of antidepressants in patients with chronic liver disease or liver transplantation. Aliment Pharmacol Ther 2014;40:880-92.

10. Nardelli S, Pentassuglio I, Pasquale C, et al. Depression, anxiety, and alexithymia symptoms are major determinants of health- related quality of life (HRQoL) in cirrhotic patients. Metab Brain Dis 2013;28:239-43.

11. European Association for the Study of the Liver. Electronic address: easloffice@easloffice.eu; European Association for the Study of the Liver. EASL Recommendations on Treatment of Hepatitis C 2018. J Hepatol 2018;69:461-511.

12. Adinolfi LE, Nevola R, Lus G, et al. Chronic hepatitis C virus infection and neurological and psychiatric disorders: an overview. World J Gastroenterol 2015;21:2269-80.

13. Younossi $Z$, Henry L. The impact of the new antiviral regimens on patient reported outcomes and health economics of patients with chronic hepatitis C. Dig Liver Dis 2014;46 Suppl 5:S186-96.

14. Rogal SS, Mankaney G, Udawatta V, et al. Pre-transplant depression is associated with length of hospitalisation, discharge disposition, and survival after liver transplantation. PLoS One 2016;11:e0165517.

15. von Glischinski M, von Brachel R, Hirschfeld G. How depressed is "depressed"? A systematic review and diagnostic meta-analysis of optimal cut points for the Beck Depression Inventory revised (BDI-II). Qual Life Res 2019;28:1111-8.

16. Cruz-Jentoft AJ, Bahat G, Bauer J, et al. Sarcopenia: revised European consensus on definition and diagnosis. Age Ageing 2019;48:16-31.

17. Nishikawa H, Shiraki M, Hiramatsu A, et al. Japan Society of Hepatology guidelines for sarcopenia in liver disease (1st edition): Recommendation from the working group for creation of sarcopenia assessment criteria. Hepatol Res 2016;46:951-63.

18. Sinclair M, Gow PJ, Grossmann M, et al. Review article: sarcopenia in cirrhosis- aetiology, implications and potential therapeutic interventions. Aliment Pharmacol Ther 2016;43:765-77.
19. Nishikawa H, Enomoto H, Ishii A, et al. Elevated serum myostatin level is associated with worse survival in patients with liver cirrhosis. J Cachexia Sarcopenia Muscle 2017;8:915-25.

20. Dasarathy S, Merli M. Sarcopenia from mechanism to diagnosis and treatment in liver disease. J Hepatol 2016;65:1232-44.

21. Hsu CS, Kao JH. Sarcopenia and chronic liver diseases. Expert Rev Gastroenterol Hepatol 2018;12:1229-44.

22. Nishikawa H, Enomoto H, Nishiguchi S, et al. Liver Cirrhosis and Sarcopenia from the Viewpoint of Dysbiosis. Int J Mol Sci 2020;21:5254.

23. Bunchorntavakul C, Reddy KR. Review article: malnutrition/sarcopenia and frailty in patients with cirrhosis. Aliment Pharmacol Ther 2020;51:64-77.

24. Kim G, Kang SH, Kim MY, et al. Prognostic value of sarcopenia in patients with liver cirrhosis: A systematic review and meta-analysis. PLoS One 2017;12:e0186990.

25. van Vugt JLA, Buettner S, Alferink LJM, et al. Low skeletal muscle mass is associated with increased hospital costs in patients with cirrhosis listed for liver transplantation-a retrospective study. Transpl Int 2018;31:165-74.

26. Nishikawa H, Enomoto H, Yoh K, et al. Association between Sarcopenia and Depression in Patients with Chronic Liver Diseases. J Clin Med 2019;8:634.

27. Chang KV, Hsu TH, Wu WT, et al. Is sarcopenia associated with depression? A systematic review and meta-analysis of observational studies. Age Ageing 2017;46:738-46.

28. Fukui H, Saito H, Ueno Y, et al: Evidence-based clinical practice guidelines for liver cirrhosis 2015. J Gastroenterol 2016;51:629-50.

29. Kokudo N, Takemura N, Hasegawa K, et al. Clinical practice guidelines for hepatocellular carcinoma: The Japan Society of Hepatology 2017 (4th JSH-HCC guidelines) 2019 update. Hepatol Res 2019;49:1109-13.

30. Drafting Committee for Hepatitis Management Guidelines, the Japan Society of Hepatology. Japan Society of Hepatology Guidelines for the Management of Hepatitis B Virus Infection: 2019 update. Hepatol Res 2020;50:892-923.

31. Wu MK, Hsu LW, Huang KT, et al. Assessment of relevant factors with respect to psychosocial properties in potential living donor candidates before liver transplantation. Neuropsychiatr Dis Treat 2018;14:1999-2005.

32. Beck AT, Ward CH, Mendelson M, et al. An inventory for measuring depression. Arch Gen Psychiatry 1961;4:561-71. 
33. Kojima M, Furukawa TA, Takahashi H, et al. Crosscultural validation of the Beck depression inventory-II in Japan. Psychiatry Res 2002;110:291-9.

34. Jay CL, Butt Z, Ladner DP, et al. A review of quality of life instruments used in liver transplantation. J. Hepatol 2009;51:949-59.

35. Härter M, Baumeister H, Reuter K, et al. Increased 12month prevalence rates of mental disorders in patients with chronic somatic diseases. Psychother Psychosom 2007;76:354-60.

36. Li F, Li Y, Duan Y, et al. Myokines and adipokines: involvement in the crosstalk between skeletal muscle and adipose tissue. Cytokine Growth Factor Rev 2017;33:73-82.

37. Breen L, Phillips SM. Skeletal muscle protein metabolism in the elderly: Interventions to counteract the 'anabolic resistance' of ageing. Nutr Metab (Lond) 2011;8:68.

38. Younossi ZM, Boparai N, Price LL, et al. Healthrelated quality of life in chronic liver disease: the impact of type and severity of disease. Am J Gastroenterol

Cite this article as: Nishikawa H, Yoh K, Enomoto H, Ikeda N, Takashima T, Aizawa N, Nishimura T, Nishiguchi S, Iijima $H$. Reduced grip strength is associated with progression of depressive status in chronic liver diseases. Ann Palliat Med 2021;10(4):3976-3987. doi: 10.21037/apm-20-2059
2001;96:2199-205.

39. Younossi Z, Henry L. Overall health-related quality of life in patients with end-stage liver disease. Clin Liver Dis (Hoboken) 2015;6:9-14.

40. Hanai T, Shiraki M, Imai K, et al. Reduced handgrip strength is predictive of poor survival among patients with liver cirrhosis: A sex-stratified analysis. Hepatol Res 2019;49:1414-26.

41. Flood A, Chung A, Parker H, et al. The use of hand grip strength as a predictor of nutrition status in hospital patients. Clin Nutr 2014;33:106-14.

42. Chen LK, Liu LK, Woo J, et al. Sarcopenia in Asia: consensus report of the Asian Working Group for Sarcopenia. Among authors: arai h. J Am Med Dir Assoc 2014;15:95-101.

43. Manthravadi S, Paleti S, Pandya P. Impact of sustained viral response postcurative therapy of hepatitis C-related hepatocellular carcinoma: a systematic review and metaanalysis. Int J Cancer 2017;140:1042-9. 